This is an electronic reprint of the original article. This reprint may differ from the original in pagination and typographic detail.

Author(s): Brabant, Olivier

Title: $\quad$ More than meets the Eye : Towards a Post-materialist Model of Consciousness

Year: $\quad 2016$

Version:

Please cite the original version:

Brabant, O. (2016). More than meets the Eye : Towards a Post-materialist Model of Consciousness. Explore : The Journal of Science and Healing, 12(5), 347-354. https://doi.org/10.1016/j.explore.2016.06.006

All material supplied via JYX is protected by copyright and other intellectual property rights, and duplication or sale of all or part of any of the repository collections is not permitted, except that material may be duplicated by you for your research use or educational purposes in electronic or print form. You must obtain permission for any other use. Electronic or print copies may not be offered, whether for sale or otherwise to anyone who is not an authorised user. 


\section{More than meets the eye: Toward a post-materialist model of consciousness}

Author: Olivier Brabant, Department of Music, University of Jyväskylä, Finland

Link to the published article: $\underline{\text { doi:10.1016/j.explore.2016.06.006 }}$

(C) 2016. This manuscript version is made available under the CC-BY-NC-ND 4.0 license http://creativecommons.org/licenses/by-nc-nd/4.0/ 


\section{Abstract}

Commonly accepted models of human consciousness have substantial shortcomings, in the sense that they cannot account for the entire scope of human experiences. The goal of this article is to describe a model with higher explanatory power, by integrating ideas from psychology and quantum mechanics. In the first part, the need for a paradigm change will be justified by presenting three types of phenomena that challenge the materialistic view of consciousness. The second part is about proposing an alternative view of reality and mind-matter manifestation that is able to accommodate these phenomena. Finally, the ideas from the previous parts will be combined with the psychological concepts developed by Frederic W. H. Myers. The result is a more comprehensive model of human consciousness that offers a novel perspective on altered states of consciousness, genius, and mental health.

\section{Keywords}

consciousness, post-materialism, mind-matter manifestation, non-locality, subliminal self 
"It is time to relinquish scientific materialism and move on to transcendent interpretations of reality that will hopefully be more productive for understanding consciousness”.

-Imants Barušs, Beyond Scientific Materialism ${ }^{1(\mathrm{p} 219)}$

\section{Time for a new paradigm}

Since the birth of modern science in the $17^{\text {th }}$ century, materialism has firmly established itself as the dominant worldview and leading scientific assumption of the Western world. Materialism is the metaphysical position that physical matter is the primary reality and subjective experiences such as consciousness, thoughts, and feelings are only a by-product of material interactions. Consequently, one deeply-ingrained belief is that we presumably live in an objective reality made of hard and tangible matter. However, the scientific revolution that began in the early $20^{\text {th }}$ century with the introduction of quantum mechanics is forcing us to reconsider this view.

Indeed, as soon as we enter the world of sub-atomic particles, all the stability and certainty that characterize the classical world suddenly vanish, and we are left with only uncertainty and unmanifested potentials. To quote the physicist Henry Stapp, “[R]eality is not made out of any material substance, but rather out of 'events' (actions) and 'potentialities' for these events to occur."2(pp26-27) An additional lesson learned from quantum mechanics is that the classical world as a whole represents a narrowed-down version of the quantum world, a limited selection from an underlying field of countless possibilities. As stated by Niels Bohr during a conversation with Werner Heisenberg in 1927, “The objective world of nineteenth-century science was, as we know today, an ideal, limiting case, but not the whole reality."3(p88)

By demonstrating the existence of a broader and hidden reality underlying our everyday reality, physicists were subsequently confronted with the problem of having to explain how these two realms interact. The traditional view has been to avoid this problem altogether, by considering the microscopic and macroscopic worlds as completely separate, effectively partitioning reality into two non-overlapping realms, each following its own rule book (quantum physics versus classical physics). On the face of it, the use of distinct rule books appears justified, as the features of the microscopic world (oneness, indeterminism, uncertainty, non-locality, interconnectedness, and time symmetry) seem incompatible with the features of the macroscopic world (multiplicity, determinism, quasi-certainty, locality, apparent separateness, and unidirectional arrow of time).

However, recent findings in the new field of quantum biology ${ }^{4}$ strongly suggest that quantum phenomena are actually much more relevant for our everyday lives than we previously thought. For instance, plants seem to be able to optimize the transportation of energy obtained through photosynthesis by using quantum superposition to "test" all the possible pathways simultaneously, and retroactively choosing the most efficient one. ${ }^{5}$ There is also evidence suggesting that migrating birds possess in their eyes a photochemical mechanism based on quantum entanglement that allows them to sense the orientation of Earth's magnetic field. ${ }^{6}$ These findings indicate that the separation between quantum and classical world is far from being clear-cut and impermeable.

Given all these developments in physics and biology, it is surprising that, for the most part, 
we are still tacitly holding on to outdated assumptions to explain reality and conduct science. A better starting point would be to integrate the fact that the fundamental nature of reality is nonphysical and governed by rules that differ from the rules governing our macro-level reality, thus allowing for a redefinition of the relationship between mind and matter. This would constitute the framework of a post-materialist approach, as defined in the "Manifesto for a post-materialist science"7.

The reluctance to adopt a post-materialist paradigm is especially problematic for consciousness studies, because reducing mind to matter only allows us to explain a limited range of human experiences. Indeed, materialism leads us to regard the human mind as an epiphenomenon of brain activity — a simple by-product of neurons firing —, with no ability to be a causal agent in its own right. However, if the theory that the brain produces consciousness were correct, then it should be impossible for certain experiences and phenomena to occur.

As we will see in the next part, there exists at least three types of phenomena which directly challenge this theory. The first type is probably the most accepted of the three, and concerns the numerous situations where the mind is able to influence the body. The second type includes all the known cases where more awareness or consciousness is accompanied by less (or no) brain activity. Finally, the last type includes all the instances where information acquisition appears to happen "outside" the brain.

\section{Mind-over-body influences}

Over the past few decades, a growing amount of mind-over-body influences have been documented. Some of them involve physical changes resulting from voluntarily directing our attention and focus. We know for example that meditation can induce physical changes in the brain ${ }^{8,9}$ and directly affect the expression of genes. ${ }^{10,11}$ Some other studies have shown that simply holding a belief can be conducive to physical changes. For instance, in a study humorously entitled "Mind over milkshakes," ${ }^{12}$ Crum et al found that the amount of ghrelin (a hunger-regulating peptide) produced in the gut did not depend on the objective caloric content of the consumed milkshakes, but on what the participants believed this content to be.

The best-documented phenomenon related to the power of belief is probably the placebo effect, ${ }^{13}$ which refers to positive physiological changes triggered by the expectation of a therapeutic benefit. No less impressive is its malevolent equivalent, namely the nocebo effect. Its most extreme manifestation is the phenomenon known in anthropological literature as "voodoo death." 14 Also called "taboo death" 15 or "psychogenic death," 16 these terms refer to the phenomenon of sudden death brought about by the firm belief in the hopelessness of a given situation. Typically, voodoo death can occur when people think they have been cursed or lost their soul, or after having broken a social taboo that irremediably transforms them into outcasts. Interestingly, this process can be easily reversed, as evidenced by the numerous reports of people close to death following a hex, who promptly recover when the spell is broken by something or someone deemed more powerful. ${ }^{15(\text { chap5), } 17}$

As shown by the previous examples, the hypothesis that the human mind should be considered causally ineffective or even entirely illusionary not only conflicts with our everyday 
experience, it is being refuted by a plethora of intention-based and belief-based phenomena, the most radical one being the mind's ability to cause the demise of the body.

\section{When less is more}

Because of the assumption that consciousness, cognition and subjective experiences are produced by the brain, neuroimaging studies are usually designed to detect an increase in brain activity, not a decrease. Especially during the first decade following the introduction of functional magnetic resonance imaging (fMRI) in the early 1990's, the prevailing methodology consisted in subtracting functional images of the brain at rest from images taken during a task, with the difference representing activity increases.

However, in the late 1990's, some researchers ${ }^{18}$ started to perform the opposite contrast (control minus task), and discovered that certain tasks were systematically accompanied by an activity decrease in specific brain areas. Raichle and Snyder ${ }^{19}$ explicitly called this fact a "problem" for neuroscience, because it challenges the usual role and functions attributed to the brain. However, such a problem can still be accommodated by materialism, as long as brain deactivation in some areas is accompanied by activation in some other areas.

The true challenge begins when an increase in mental activity occurs with no brain activation anywhere. Such an astonishing outcome was reported for example by Carhart-Harris et al in a study ${ }^{20}$ investigating the effects of psilocybin (a psychedelic compound found in "magic mushrooms"). To their surprise, the psychedelic experience, with all its intense and vivid imagery, was accompanied by a widespread decrease in brain activity and connectivity, and not a single area

of increase. Even more surprising was the inverse relationship between brain activity and subjective experience: the lower the brain activity, the more intense the experience reported by the participant.

Needless to say, under materialism, such findings are highly counter-intuitive. As the theory goes, if conscious experiences are produced by the brain, then a more intense experience must correlate with a corresponding activity increase somewhere in the brain. However, in this specific study, the authors made the exact opposite discovery (no activation whatsoever, and a negative correlation between brain and mind). But the challenge does not end here.

In the previous example, although brain activity did not increase, there was presumably enough activity present to enable what is known as the neural correlates of consciousness (NCC). Neuroscience calls NCC the minimal neuronal activity and mechanisms that are sufficient to give rise to conscious experience. Under that threshold, any form of conscious experience is deemed impossible. However, the NCC hypothesis is no longer tenable when considering what is arguably the most radical disconnect between brain and mind, namely the numerous cases of near-death experience (NDE) reported by survivors of cardiac arrest.

Although NDEs can occur in connection with other life-threatening situations or medical conditions, what makes the context of cardiac arrest particularly interesting is the fact that the survivors were clinically dead for a certain period of time, yet $10-20 \%$ of them vividly remember having had a profound subjective experience. ${ }^{21}$ The most typical features of NDEs are positive emotions, an awareness of being dead, an encounter with deceased relatives, moving through a tunnel, seeing a bright light, an out-of-body experience, and a life review. ${ }^{22,23}$ 
Many biological explanations of NDEs have been suggested, such as anoxia (absence of oxygen supply), hypercarbia (elevated levels of carbon dioxide), massive endorphin release, and altered temporal lobe functioning. ${ }^{22}$ However, if the various physiological changes that occur during cardiac arrest are indeed causing NDEs, how come NDEs are only happening in 10-20\% of the cases? Other authors have pointed out that the proposed psychophysiological explanations do not account for the entire phenomenology of NDEs, at best certain features, and even here the similarities appear contrived. ${ }^{24(\text { chap6) }}$

The strongest objection to the various biological explanations is the fact that NDEs happen at a time when the brain is at best heavily impaired, and at worst non-functioning. Both are times when, according to modern neuroscience, there should not be any awareness, cognitive process or memory formation whatsoever. But empirical data shows that memory formation does occur during NDEs, and that these memories appear to be reliable and very stable over time. ${ }^{25,26}$ Even more astonishingly, a great majority of near-death experiencers report levels of mental clarity that are equal or superior to those of their normal waking state, as well as faster thinking. ${ }^{24(\mathrm{chap} 6)}$

One major challenge affecting NDE research is the difficulty in establishing an accurate timeline of the events. Did the NDE indeed occur while the person was clinically dead (i.e. while having no measurable brain activity)? Alternatively, could it have happened just before clinical death or right after resuscitation, when the brain was at least partly functional? If the latter were always true, then materialists could still claim that there might exist a brain-based explanation. However, corroborated reports ${ }^{27-29}$ of patients remembering detailed events that really occurred while they were clinically dead suggest that—at least in those cases—some form of consciousness must have existed during those events.

Evidently, the findings of NDE research glaringly contradict the tenets of (materialist) neuroscience. To summarize, it would appear that our mind can exist—at least for a short whileseparately from our brain, and at the same time experience a form of enhanced awareness. Such findings lend support to the so-called filter theories, ${ }^{30}$ whereby the brain should be seen as having more an eliminative than a productive function, filtering out most of what could theoretically be perceived or remembered.

\section{New information beyond the brain}

In this part I would like to challenge the widespread notion ${ }^{31(\text { chap5) }}$ that new ideas or solutions necessarily result from combining and reorganizing existing knowledge obtained from prior experience. A good place to start would be to consider the mind-boggling skills displayed by people with savant syndrome.

Savant syndrome is a rare condition where developmental disabilities co-exist alongside prodigious skills in very specific areas, usually music, mathematics, and calendar calculations. ${ }^{32}$ The fact that such extraordinary skills are accessible to some people raises the question of whether these abilities are potentially present in all of us, and what could be done to tap into them. But even more fundamentally, the great mystery surrounding savant syndrome is to explain how they do it. Although some skills could indeed be explained by postulating the existence of enhanced forms of known brain functions, certain skills clearly defy such explanations. The case of Daniel Tammet 
will serve to illustrate this point.

Daniel Tammet is a high-functioning autistic savant with prodigious language-learning and mathematical skills. He is also gifted with a form of synaesthesia that makes him perceive each number as a specific shape, texture, and color. In his eloquent autobiography, he describes how he performs calculations using the shapes that populate his mental world. It is important to stress that Daniel Tammet does not actually perform calculations in the traditional sense. As baffling as it may sound, the right answers just appear to him, effortlessly and almost instantly. "When multiplying, I see the two numbers as distinct shapes. The image changes and a third shape emerges - the correct answer. The process takes a matter of seconds and happens spontaneously. It's like doing maths without having to think."33(pp4-5)

In other words, Daniel Tammet's brain is not merely a number-crunching supercomputer. Rather, he appears to have access to another realm of information from where he simply retrieves the correct mathematical answers. Moreover, his case is far from being unique. If we examine all the known cases of autistic savants with prodigious mathematical skills that have been documented since the $19^{\text {th }}$ century, some recurrent features are the instantaneity of the process, the absence of voluntary effort, and an unawareness of how the correct answer is obtained. ${ }^{24(\text { chap7),32 }}$

Another striking example of knowledge or information seemingly obtained from "outside" the brain are all the documented cases of people who know things they never learned or were never exposed to. As illustrated by Treffert, ${ }^{34}$ this phenomenon is not limited to savant syndrome, but can also occur in people with no co-existing disability. He mentions the case of Jay Greenberg, a musical prodigy who asked for a cello at the age of two, immediately knew how to play it, and soon after started writing down musical compositions. By the age of 12, Jay had already composed five full-length symphonies, and his $5^{\text {th }}$ Symphony was subsequently recorded by the London Symphony Orchestra. It should be added that Jay's parents are not musical, and that he had never been exposed to any music instrument in his early childhood.

What makes this case very relevant to our discussion is the fact that Jay Greenberg is not composing music in the traditional sense. In an interview for the 60 Minutes television program, ${ }^{35}$ he describes how musical pieces appear fully-formed in his head-sometimes several pieces simultaneously_- and that he just needs to write them down, without ever having to make any corrections afterward. Similar to Daniel Tammet and his mathematical answers, it seems that Jay Greenberg is simply “downloading” finished musical pieces into his mind.

Again, this way of composing music, albeit rare, is certainly not unique. A similar type of inspiration has been reported by other famous composers, such as Johannes Brahms, who stated that "not only do I see distinct themes in the mind's eye, but they are clothed in the right forms, harmonies, and orchestration. Measure by measure the finished product is revealed to me when I am in those rare inspired moods."36(p21) Such a composition process, apart from being unconventional, obviously raises the question of the actual source of the music. The possibility that music might sometimes be received by the human mind instead of being produced by it hints at the existence of an information realm located outside the physical brain, thus posing a further challenge to materialist models of human consciousness. 


\section{An alternative to materialism}

As we have seen, the conventional approach where the brain produces consciousness $(A \Rightarrow B)$ is not able to account for a wide range of human experiences. Therefore, a better model should regard all the already established neural correlates as nothing else but pure correlations, and not imply any unidirectional causality. The best way to achieve this is to assume the existence of an underlying third factor causing both ( $\Rightarrow A, B$ ), with $A$ and $B$ being only different aspects of $C$ (see Figure 1).

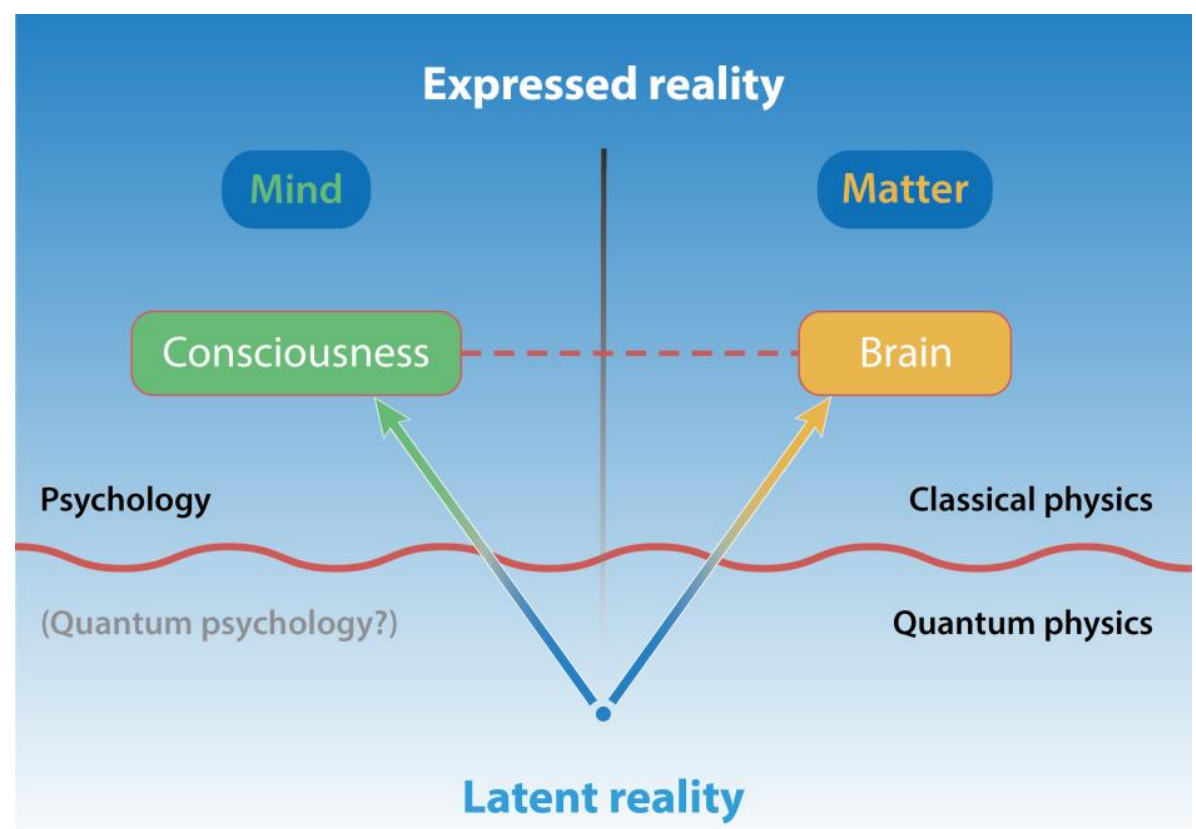

Figure 1. Proposed model of mind-matter manifestation. The fuzziness of the separation between quantum and classical world is symbolized by a line that is wavy instead of straight.

In this model, mind and matter are not viewed as two interacting substances, but as correlated projections from a common ground located in the quantum world. Such a view has been extensively elaborated upon by physicist David Bohm, for whom "mind and matter are not separate substances", but "different aspects of one whole and unbroken movement." ${ }^{37(p 14)}$ He gave the name "implicate order" to this fundamental substrate out of which the "explicate order" (our macro-level reality) unfolds. Bohm envisaged the implicate order as a non-local and unified field containing what he called "active information", whose purpose is to guide the manifestation of physical and mental processes. ${ }^{38}$ Active information would thus serve as a bridge between the mental and physical sides of reality, seen by Bohm as inseparable.

In accordance with these ideas, the latent reality could be defined as a non-local and selforganizing field of potentialities, where information is being constantly added to and retrieved from. In other words, the ground stuff of the universe should not be seen as a concrete and immutable "thing”, but as a process that involves a pool of information constantly reorganizing itself, waiting to take shape and manifest (it is literally "in-formation”). According to Stapp, "Each subjective experience injects one bit of information into this objective store of information, which then specifies, via known mathematical laws, the relative probabilities for various possible future 
subjective experiences to occur.”39(p268)

This bidirectional exchange of information could be compared to a giant feedback loop that constantly modifies the probability of any potential event to occur, the general rule being that the more something has already happened, the more likely it is to happen again. In other words, at the core of our psychophysical reality, we find a mechanism of repetition and reinforcement that ultimately leads to something highly stable and predictable. However, nothing is truly permanent, and something that appears very stable now can suddenly or progressively become less so.

Before proceeding further, it is important to realize that the process of mind-matter manifestation described above is far from being a minority view. On the contrary, these ideas are progressively becoming more understood and accepted, as can be seen from the Potsdam Manifesto 2005*:

The immaterial, information-bearing, pre-living interconnections prevailing in the microworld are only indirectly operative on the meso-level of our world of experience. Usually they average out and, in this "diffused" form, express themselves in the familiar, "classical" behavior of inanimate nature.... Animate nature draws its ability for continued, creative differentiate and cooperative integration from its "pre-living” (microphysically recognizable) primordial ground, whose "information", through instabilities, rises enhanced into the meso-sphere, where it unfolds in more intense and richer form. The "pre-living" realm thus organizes itself in the complex variety of our "higher" bio-ecological vibrancy, as we encounter it in everyday life. ${ }^{40(p 63)}$

This manifesto was written under the patronage of the Federation of German Scientists (VDW), and signed by more than 130 scientists and personalities from around the world. When taken together with the "Manifesto for a post-materialist science", it would appear that we are indeed on the verge of a long-overdue paradigm shift, in the sense of Thomas Kuhn's theory of scientific revolutions. ${ }^{41}$

It is noteworthy that many physicists have chosen to describe the primordial ground stuff with terms usually reserved for the human mind, such as proto-consciouness, ${ }^{42}$ mindful universe ${ }^{2}$ selfaware universe, ${ }^{43}$ and mental universe. ${ }^{44}$ Such concepts are somewhat misleading, as they give the impression that the latent reality is conscious in the same way a human is conscious. What all these authors are actually saying is that the fundamental level of reality is of the nature of consciousness. To avoid any confusion, I believe it is important to bypass people's anthropocentric tendencies and choose a less ambiguous terminology. Consequently, from this point on, I will only use the terms “consciousness" and "mind” in relationship to humans. Furthermore, I will use "consciousness” in the sense of "awareness" and "experiential stream of everyday consciousness". As to "mind", it encompasses everything the person is presently aware of, as well as all the things that could potentially enter consciousness but currently do not.

The next step is to describe what elements pertaining to human consciousness and individual psyches could actually be located in the quantum world, and to propose a mechanism explaining the

\footnotetext{
* The Potsdam Manifesto was meant to commemorate the famous Russell-Einstein-Manifesto of 1955, which was a call for a new way of thinking that would guarantee world peace.
} 
information exchange between the visible, expressed reality and the invisible, potential reality. In order to do so, I will use the ideas and terminology developed by Frederic W. H. Myers in the late $19^{\text {th }}$ century, and combine them with the contemporary scientific concepts presented above.

\section{Subliminal and supraliminal}

Although initially trained as a philologist and classicist, Myers devoted the last two decades of his life to empirical research in psychology. During this time, he thoroughly investigated a wide range of human experiences - from the most common to the strangest and most unusual ones-, with a view to developing a theory of the human mind that would explain and accommodate all of them. This led him to propose an interesting alternative to the commonly accepted division in conscious and unconscious parts, which has been popularized by Sigmund Freud's psychoanalytic theory. ${ }^{45}$

Instead of opposing conscious to unconscious mental content, Myers prefers using the notions of supraliminal and subliminal. According to him, the supraliminal would be the equivalent of our "normal” waking consciousness, whereas the subliminal represents our larger and latent self, of which the supraliminal self is only a stabilized extract. ${ }^{24(\text { chap2) }}$ He defines the subliminal self as "a more comprehensive consciousness, a profounder faculty, which for the most part remains potential only so far as regards the life of earth, but from which the consciousness and the faculty of earthlife are mere selections." $46(\mathrm{p} 13)$

We encounter again the idea that the manifested, supraliminal reality is always the result of a narrowing-down of something larger. Furthermore, this topology implies the existence of a barrier or threshold: above it, we find what is being expressed now and has entered waking consciousness; under it, we find what is not currently expressed but could potentially be, given the right circumstances. As we can see, Myers is in fact inadvertently and precociously applying to human consciousness the above-mentioned principles of mind-matter manifestation.

It is important to add that in Myers' view, although it appears to us as being mostly stable, this threshold is actually in a state of subtle flux and shifting equilibrium. Under certain circumstances, the "liminal stability" might change, suddenly allowing the expression of a higher or lower amount of subliminal content than usual. According to Myers, an "instability of the psychical threshold”46(p53) can have various outcomes, depending on the amount of emergence and submergence from/to the subliminal.

In the case of a narrowing of consciousness, which could be described as a loss of threshold permeability or a higher-than-usual “down-draught”46(p53) from the supraliminal into the subliminal, a person might for example develop symptoms of what used to be called hysteria, nowadays known as conversion disorder. ${ }^{4(\sec F 44)}$ The most common symptoms would be a dissociated personality, loss of memory, insensibility to pain (local or general), paralysis, and blindness, but without there being any apparent physical cause. Applying Myers’ ideas, conversion disorder can be understood as someone's consciousness not fully manifesting out of the subliminal and partly desynchronizing with its physical counterpart (the corresponding body), leading to a loss of awareness of what the body is doing.

Conversely, when the threshold becomes more permeable than usual — the equivalent of an expansion of consciousness-, new information can enter our awareness and formerly unexpressed 
abilities or ideas might suddenly emerge. Myers talks about an "uprush"46(p53) from the subliminal into the supraliminal, and if a person can fully reap the benefits of this process, then typically that person would be called a genius. Indeed, genius could be defined as the ability to utilize a wider range of subliminal information and not become unsettled or overwhelmed in the process of doing so.

\section{Model overview}

Once it has become clear that the informational ground stuff is the ultimate source of both the world's material structures and the experiences of sentient beings within it, nothing speaks against attempting to unify quantum physics and psychology. On the contrary, it even becomes a scientific necessity. Actually, such a reconciliation has already been suggested by psychologist Carl Jung and physicist Wolfgang Pauli in the late 1940's, whose collaboration led to a philosophical proposition known nowadays as the Pauli-Jung conjecture. ${ }^{48}$

As we have seen, the fundamental notion underlying the proposed model is the idea that mind and matter arise from the same unitary source, of which they represent two complementary aspects. This approach makes it possible to merge the thresholds partitioning consciousness and physical reality into one. From that point of view, the threshold described by Myers can be equated with the separation between quantum and classical reality. Should we accept these premises, then the logical conclusion is that our subliminal mind resides in the quantum level of reality and therefore shares all of its properties, whereas manifested consciousness functions within the laws of classical physics.

Using Figure 1 as a starting point, human consciousness could be depicted by adding a triangle, as seen in Figure 2. The tip of the triangle represents the supraliminal self, whereas the part below the manifestation threshold represents the subliminal self. If we duplicate the triangle and place a copy of it above the threshold, then the distance between the smaller triangle (supraliminal self) and the larger triangle (subliminal self) represents the currently unexpressed potential.

As for the upward and downward arrows, they illustrate the idea of a constant information exchange between the supraliminal and subliminal realms. This exchange is required to obtain the feedback loop mentioned earlier, whereby information patterns are constantly being extracted, modified and reinforced. Thus, the two arrows represent the two functions of the subliminal self, which is to be an informational blueprint (upward arrow) as well as an information collector (downward arrow). 


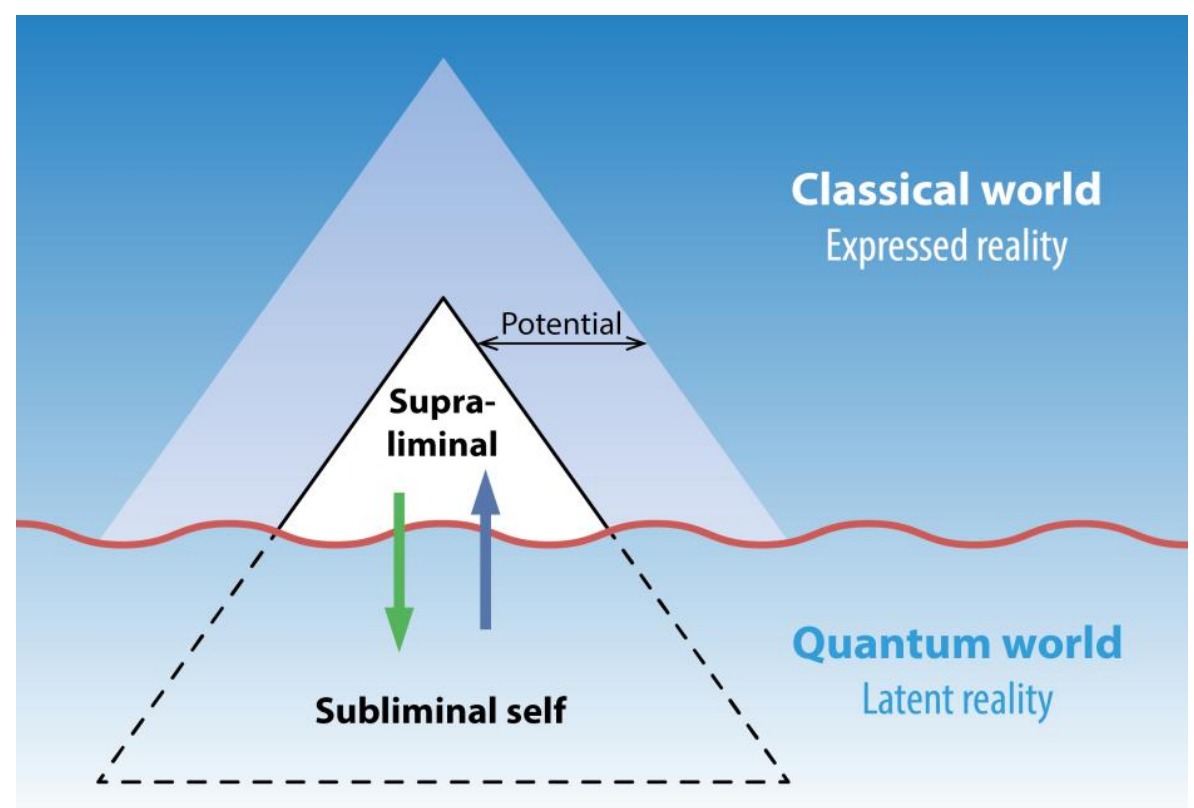

Figure 2. Individual human mind, whose expressed part (supraliminal self) is seen as a stabilized extract from an underlying realm of psychophysical potentialities (subliminal self).

The term "information collector" highlights the idea that every individual experience leaves a trace on the subliminal level, where it remains forever stored. Such a view is actually not new, but has already been expressed in the mid-19 ${ }^{\text {th }}$ century by Gustav Fechner, pioneer in experimental psychology and father of psychophysics. He postulated the existence of "a great reservoir in which the memories of earth's inhabitants are pooled and preserved, and from which, when the threshold lowers or the valve opens, information ordinarily shut out leaks into the mind of exceptional individuals among us."49(p135)

As to the concept of "informational blueprint", it bears many similarities to the hypothesis of morphic fields, which can be defined as patterns of information that shape psychophysical reality by guiding the manifestation process. ${ }^{50}$ Similarly to quantum fields, they work probabilistically and modify the indeterminism of the system they influence. One of the theoretical properties of morphic fields is to be strengthened by previous activations, thus making further manifestations of the same kind more easy and likely. At the same time, by storing information of what has already happened, morphic fields would constitute a form of collective memory.

Until now we have been talking about the consciousness of a single individual. How would this model handle the simultaneous presence of several individuals and explain their interaction? On the supraliminal level, individual consciousnesses would appear as separate entities that have to rely on the five senses to exchange information. However, each subliminal self could be seen as being connected through a common ground, similarly to islands that appear separate above the water but are actually connected through the bottom of the ocean (Figure 3). The dashed lines in Figure 3 are meant to signify that the subliminal information belonging to one specific individual is concurrently collective information potentially accessible from anywhere by anybody. In that sense, what I call here "common ground" has many similarities with Carl Jung's concept of the collective unconscious. ${ }^{51}$ 


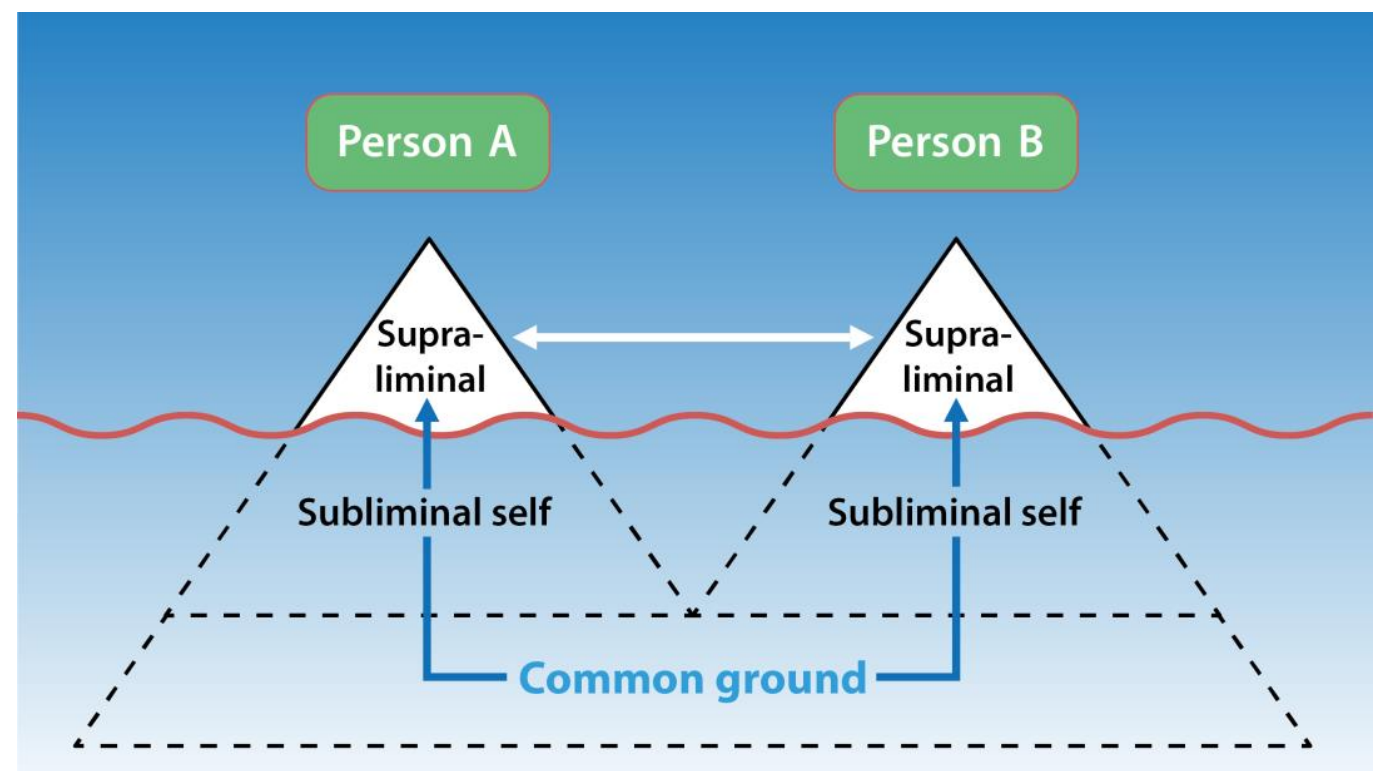

Figure 3. Interconnectedness of seemingly separate individual consciousnesses. The arrows represent the two possible modes of information exchange and acquisition.

Assuming that everything on the subliminal/quantum level is characterized by oneness, interconnectedness and non-linear space-time, it then becomes possible for the subliminal mind to have access to information beyond the normal range of the senses, and not be dependent on the brain in order to do so. This would offer an explanatory framework for the phenomena presented above, as well all for other phenomena considered until now as anomalous by mainstream science, such as extrasensory perception (psi). It should also be noted that similar models of information acquisition and mind-matter interaction have already been proposed in the past, for instance the $\mathrm{M}^{5}$ model developed by Jahn and Dunne. ${ }^{52}$

\section{Implications}

Undoubtedly, should the model of consciousness presented above become widely accepted, it would profoundly change the way we relate to each other and to the world around us. It would also revolutionize the way we understand health and disease, and lend legitimacy to holistic healing modalities, still largely seen as an inferior type of medicine. In particular, it would offer a new and useful perspective on altered states of consciousness (ASC) and mental health.

Indeed, in a healthy adult, the threshold separating supraliminal and subliminal self has become largely stable and only changes punctually and in a predictable manner, as illustrated by the daily cycle of waking, dreaming, and deep sleep. However, we also have access to a wide number of non-ordinary states of consciousness, some being enjoyable, desirable, and useful, while others are considered distressful, dangerous, and taboo. As explained by Charles Tart, ${ }^{53}$ every human culture selects and reinforces certain states of consciousness, while rejecting and inhibiting others, thus extensively shaping and limiting the type of experience an adult member of this society will be able or allowed to have.

This is precisely what makes geniuses and prodigies so exceptional: they have a natural and 
easy access to a certain type of subliminal information (individual and/or collective), while most people can only access that information sometimes, either randomly or after having purposefully entered an ASC. The latter would be the case of shamans, who use specific consciousness-altering rituals in order to initiate a vision quest or a shamanic journey, from which they expect to gain new knowledge that will be useful to their community.

To summarize, any change in state of consciousness can be defined as a change in threshold permeability. The actual question then becomes, what kind of information or pattern comes through or disappears, and in what amount? Therefore, changes in liminal stability are in themselves neither good nor bad. Whether such a change is experienced as pathological or beneficial ultimately depends on when it happens, how often, the level of control over it, and the advantages or disadvantages derived from it. Another important factor is the way the experience is framed and contextualized by the culture we live in. ${ }^{54,55}$

This last point is in line with cognitive models of psychosis, ${ }^{56,57}$ whereby the outcome of anomalous or psychotic-like experiences ultimately depends on how they are understood and appraised by the person having them. Such a perspective is supported by the many similarities that have been observed between the early symptoms of schizophrenia and the ASC induced by psychedelics in healthy individuals, ${ }^{58}$ or more generally by the fact that every pathological ASC also has a non-pathological equivalent. ${ }^{59}$

\section{Acknowledgments}

The author wishes to thank Jaakko Erkkilä and Petri Toiviainen for their valuable comments, and Elsa Campbell for proofreading the initial draft of this article.

\section{References}

1. Barušs I. Beyond scientific materialism: Toward a transcendent theory of consciousness. $J$ Conscious Stud. 2010;17(7-1):213-231.

2. Stapp HP. Mindful Universe: Quantum Mechanics and the Participating Observer. 2nd ed. Berlin: Springer; 2011.

3. Heisenberg W. Physics and beyond: Encounters and Conversations. New York, NY: Harper \& Row; 1971.

4. Lambert N, Chen Y-N, Cheng Y-C, Li C-M, Chen G-Y, Nori F. Quantum biology. Nat Phys. 2013;9(1):10-18. doi:10.1038/nphys2474.

5. Engel GS, Calhoun TR, Read EL, et al. Evidence for wavelike energy transfer through quantum coherence in photosynthetic systems. Nature. 2007;446(7137):782-786. doi:10.1038/nature05678.

6. Ritz T. Quantum effects in biology: Bird navigation. Procedia Chem. 2011;3(1):262-275. doi:10.1016/j.proche.2011.08.034. 
7. Beauregard M, Schwartz GE, Miller L, et al. Manifesto for a post-materialist science. EXPLORE J Sci Heal. 2014;10(5):272-274. doi:10.1016/j.explore.2014.06.008.

8. Hölzel BK, Carmody J, Vangel M, et al. Mindfulness practice leads to increases in regional brain gray matter density. Psychiatry Res Neuroimaging. 2011;191(1):36-43. doi:10.1016/j.pscychresns.2010.08.006.

9. Jang JH, Jung WH, Kang D-H, et al. Increased default mode network connectivity associated with meditation. Neurosci Lett. 2011;487(3):358-362. doi:10.1016/j.neulet.2010.10.056.

10. Bhasin MK, Dusek JA, Chang B-H, et al. Relaxation response induces temporal transcriptome changes in energy metabolism, insulin secretion and inflammatory pathways. PLOS ONE. 2013;8(5):e62817. doi:10.1371/journal.pone.0062817.

11. Kaliman P, Álvarez-López MJ, Cosín-Tomás M, Rosenkranz MA, Lutz A, Davidson RJ. Rapid changes in histone deacetylases and inflammatory gene expression in expert meditators. Psychoneuroendocrinology. 2014;40:96-107. doi:10.1016/j.psyneuen.2013.11.004.

12. Crum AJ, Corbin WR, Brownell KD, Salovey P. Mind over milkshakes: Mindsets, not just nutrients, determine ghrelin response. Health Psychol. 2011;30(4):424-429.

doi:10.1037/a0023467.

13. Benedetti F. Placebo Effects: Understanding the Mechanisms in Health and Disease. Oxford; New York: Oxford University Press; 2009.

14. Cannon WB. "Voodoo" death. Am Anthropol. 1942;44(2):169-181. doi:10.1525/aa.1942.44.2.02a00010.

15. Frank JD, Frank JB. Persuasion and Healing: A Comparative Study of Psychotherapy. Baltimore: Johns Hopkins University Press; 1993.

16. Dein S. Psychogenic death: Individual effects of sorcery and taboo violation. Ment Health Relig Cult. 2003;6(3):195-202. doi:10.1080/13674670310001633478.

17. Meador CK. Hex death: Voodoo magic or persuasion? South Med J. 1992;85(3):244-247.

18. Shulman GL, Fiez JA, Corbetta M, et al. Common blood flow changes across visual tasks: II. decreases in cerebral cortex. J Cogn Neurosci. 1997;9(5):648-663. doi:10.1162/jocn.1997.9.5.648.

19. Raichle ME, Snyder AZ. A default mode of brain function: A brief history of an evolving idea. NeuroImage. 2007;37(4):1083-1090. doi:10.1016/j.neuroimage.2007.02.041.

20. Carhart-Harris RL, Erritzoe D, Williams T, et al. Neural correlates of the psychedelic state as determined by fMRI studies with psilocybin. Proc Natl Acad Sci. 2012;109(6):2138-2143. doi:10.1073/pnas.1119598109.

21. Parnia S, Spearpoint K, Fenwick PB. Near death experiences, cognitive function and psychological outcomes of surviving cardiac arrest. Resuscitation. 2007;74(2):215-221. doi:10.1016/j.resuscitation.2007.01.020.

22. Agrillo C. Near-death experience: Out-of-body and out-of-brain? Rev Gen Psychol. 2011;15(1):1-10. doi:10.1037/a0021992.

23. van Lommel P. Near-death experiences: The experience of the self as real and not as an 
illusion. Ann N Y Acad Sci. 2011;1234(1):19-28. doi:10.1111/j.1749-6632.2011.06080.x.

24. Kelly EF, Kelly EW, Crabtree A, Gauld A, Grosso M, Greyson B. Irreducible Mind: Toward a Psychology for the 21st Century. Lanham, MD: Rowman \& Littlefield Publishers; 2009.

25. Greyson B. Consistency of near-death experience accounts over two decades: Are reports embellished over time? Resuscitation. 2007;73(3):407-411.

doi:10.1016/j.resuscitation.2006.10.013.

26. van Lommel P, van Wees R, Meyers V, Elfferich I. Near-death experience in survivors of cardiac arrest: A prospective study in the Netherlands. The Lancet. 2001;358(9298):20392045. doi:10.1016/S0140-6736(01)07100-8.

27. Clark K. Clinical interventions with near-death experiencers. In: Greyson B, Flynn CP, eds. The near-Death Experience: Problems, Prospects, Perspectives. Springfield, IL: Charles C. Thomas; 1984.

28. Holden JM. Veridical perception in near-death experiences. In: Holden JM, Greyson B, James D, eds. The Handbook of near-Death Experiences: Thirty Years of Investigation. Santa Barbara, CA: Praeger (ABC-CLIO); 2009:185-211.

29. Parnia S, Spearpoint K, de Vos G, et al. AWARE-AWAreness during REsuscitation-A prospective study. Resuscitation. 2014;85(12):1799-1805.

doi:10.1016/j.resuscitation.2014.09.004.

30. Dossey L. The brain as filter: On removing the stuffing from the keyhole. EXPLORE J Sci Heal. 2012;8(6):317-322. doi:10.1016/j.explore.2012.08.006.

31. Pinker S. How the Mind Works. London: Penguin Books; 1999.

32. Treffert DA. Extraordinary People: Understanding Savant Syndrome. Omahe, NE: Backinprint.com; 2006.

33. Tammet D. Born on a Blue Day: Inside the Extraordinary Mind of an Autistic Savant. New York, NY: Simon and Schuster; 2007.

34. Treffert DA. Islands of Genius: The Bountiful Mind of the Autistic, Acquired, and Sudden Savant. Reprint edition. London: Jessica Kingsley Publishers; 2011.

35. Owens B. Musical Prodigy, Bluejay. 60 Minutes. November 2006. http://www.cbsnews.com/news/bluejay-spreads-his-wings/. Accessed December 11, 2014.

36. Abell A. Talks with Great Composers. New York, NY: Philosophical Library; 1955.

37. Bohm D. Wholeness and the Implicate Order. London; New York: Routledge; 1980.

38. Bohm D. A new theory of the relationship of mind and matter. Philos Psychol. 1990;3(23):271-286. doi:10.1080/09515089008573004.

39. Stapp HP. Mind, Matter and Quantum Mechanics. 2nd ed. Berlin: Springer; 2004.

40. Dürr H-P, Dahm D, zur Lippe R. Potsdam Manifesto 2005: We Have to Learn to Think in a New Way. Munich: ökom-Verlag; 2005.

41. Kuhn TS. The Structure of Scientific Revolutions. Chicago, IL: University of Chicago Press; 
1962.

42. Hameroff S, Penrose R. Consciousness in the universe: A review of the "Orch OR" theory. Phys Life Rev. 2014;11(1):39-78. doi:10.1016/j.plrev.2013.08.002.

43. Goswami A. The Self-Aware Universe. New York: Tarcher; 1995.

44. Henry RC. The mental Universe. Nature. 2005;436(7047):29-29. doi:10.1038/436029a.

45. Freud S. The Unconscious. London: Penguin Classics; 2005.

46. Myers FWH. Human Personality and Its Survival of Bodily Death. London: Longmans, Green and Co.; 1907. https://archive.org/details/humanpersonality00myer.

47. World Health Organization. In: International Statistical Classification of Diseases and Related Health Problems, 10th Revision (ICD-10). Geneva: World Health Organization; 1993. http://apps.who.int/classifications/icd10/browse/2010/en\#/F44.

48. Atmanspacher H. Dual-aspect monism à la Pauli and Jung. J Conscious Stud. 2012;19(910):96-120.

49. James W. A Pluralistic Universe. Cambridge, MA: Harvard University Press; 1977.

50. Sheldrake R. Morphic Resonance: The Nature of Formative Causation. 4th ed. Rochester, VT: Park Street Press; 2009.

51. Jung CG. The Archetypes and the Collective Unconscious. 2nd ed. London: Routledge; 1991.

52. Jahn RG, Dunne BJ. A modular model of mind/matter manifestations $\left(\mathrm{M}^{5}\right)$. $J$ Sci Explor. 2001;15(3):299-329.

53. Tart C. States of Consciousness. Lincoln, NE: iUniverse; 2001.

54. Lukoff D. Visionary spirituality and mental disorders. In: Cardeña E, Winkelman M, eds. Altering Consciousness: Multidisiplinary Perspectives. Vol 2. Santa Barbara, CA: Praeger (ABC-CLIO); 2011:301-325.

55. Moreira-Almeida A, Cardeña E. Differential diagnosis between non-pathological psychotic and spiritual experiences and mental disorders: A contribution from Latin American studies to the ICD-11. Rev Bras Psiquiatr. 2011;33:21-28. doi:10.1590/S1516-44462011000500004.

56. Lovatt A, Mason O, Brett C, Peters E. Psychotic-like experiences, appraisals, and trauma. $J$ Nerv Ment Dis. 2010;198(11):813-819. doi:10.1097/NMD.0b013e3181f97c3d.

57. Morrison AP. The interpretation of intrusions in psychosis: An integrative cognitive approach to hallucinations and delusions. Behav Cogn Psychother. 2001;29(3):257-276. doi:10.1017/S1352465801003010.

58. Gouzoulis-Mayfrank E, Habermeyer E, Hermle L, Steinmeyer A, Kunert H, Sass H. Hallucinogenic drug induced states resemble acute endogenous psychoses: Results of an empirical study. Eur Psychiatry. 1998;13(8):399-406. doi:10.1016/S0924-9338(99)80686-5.

59. Cardeña E. Altered consciousness in emotion and psychopathology. In: Cardeña E, Winkelman M, eds. Altering Consciousness: Multidisiplinary Perspectives. Vol 2. Santa Barbara, CA: Praeger (ABC-CLIO); 2011:279-299. 